\title{
Innovation and sustainability in urban agriculture: the path forward
}

\author{
Francesco Orsini ${ }^{1}$
}

Received: 1 June 2020 / Revised: 5 June 2020 / Accepted: 18 June 2020 / Published online: 29 June 2020

(c) Bundesamt für Verbraucherschutz und Lebensmittelsicherheit (BVL) 2020

Urban Agriculture (UA) is experiencing an unprecedented growth throughout the world, finding applications in countries with both developing and more developed economies. While featuring a range of different forms, it commonly encompasses all activities of plant cultivation and animal rearing within cities and towns and in their immediate surroundings. In addition to its potential contribution to food security, UA also provides non-food products, plus a number of functionalities. Accordingly, ecosystem services associated with UA include the so called provisioning services (e.g. food supply), regulating services (e.g. involving the improvement of air or soil quality, plus flood control), habitat services (e.g. contributing to urban biodiversity), and cultural services (e.g. recreation, amenity or social inclusion).

\section{Towards multifunctional urban agriculture}

UA projects also bring innovation in available plant cultivation systems and technologies. As agriculture moves into cities, constraints arise, mainly associated with land accessibility, access to water, legal and policy frameworks and food safety (Gasperi et al. 2016). As a consequence, agricultural technology has evolved, particularly with reference to the so-called systems for building-integrated agriculture, which is also referred to as Zero-Acreage Farming (or Z-Farming). The achievement of agricultural integration within an existing urban built environment provides several advantages that not only might include a nexus to consumers and image/aesthetic functionalities, but might also contribute to circularity and overall urban metabolism. This is especially true for instance when (1) reclaimed wastewater or harvested rainwater is used for irrigation, (2) when organic waste is composted and used for plant nutrition, or (3) even when thermal

Francesco Orsini

f.orsini@unibo.it

1 DISTAL - Department of Agricultural and Food Sciences, ALMA MATER STUDIORUM, Bologna University, Bologna, Italy energy and air flows are established between environments devoted to crop production and both residential and commercial buildings. Among building-integrated agriculture systems, the most promising and innovative ones are those of rooftop agriculture and vertical farming.

\section{Farming on and inside urban buildings}

Rooftop farming, which may take the form of open-air rooftop systems or rooftop greenhouses, allows the recovery and productive transition of vacant rooftop spaces. Whereas open-air systems are often associated with leisure and recreational functions in the global North, they may assume a crucial role for food security in developing countries, where they often host simplified hydroponic systems for veg-etable production. Alternatively, rooftop greenhouses (mainly found in North America, but growing in number also in Asia and Europe), are often equipped with highly technological systems and integrate the production of quality fruits and vegetables, with services such as workshops, catering, and events.

Vertical farming systems (often referred to as Plant Factories with Artificial Lighting) are also growing in number across the globe, because of their resilience to external climatic conditions and their elevation of resource-use efficiency (especially in terms of land and water use, e.g. through use of closed loop hydroponics and recovery of atmospheric humidity and reuse for irrigation). The advances in LED lighting technologies have opened up a number of research fields that have previously mainly considered light implications for food nutritional quality and for food safety and the productivity and sustainability potential of indoor farming.

\section{Farming the city: sustainability implications and regulatory framework}

In recent years, several research groups have addressed the quantification of the economic, social and environmental sustainability of UA, including that within a framework of 
international projects. Environmental performances have been identified for a range of UA systems, from allotment gardens (Sanyé-Mengual et al. 2018) to rooftop agriculture projects (Sanyé-Mengual et al. 2015) and vertical farming systems (Pennisi et al. 2019). However, each study builds on the peculiarities and uniqueness of each project case, therefore the possibilities of driving general conclusions and of implementing widely applicable policy tools haves to date been limited (Sanyé-Mengual et al. 2019).

A main issue that hinders the growth of commercial UA is the absence or scarcity of adequate laws and regulations framing the sector. Whereas policies exist for the promotion of green spaces in the city for ecological-environmental, aesthetic-recreational, and social-educational purposes, the same cannot be said for UA oriented towards food production. As a consequence, the incorporation of UA within the food system is generally slow, because of the lack of national and local policies and strategic frameworks. Thus, a legislation is needed to ease the establishment and management of small-scale and citizen-driven UA initiatives, overarching the economic, environmental and social functions involved in achieving sustainable food systems.

From a food safety perspective, the potential risks associated with environmental pollution should be addressed when agricultural products are cultivated within the urban environment. Contamination in cities may assume the form not only of heavy metals or metalloids, but also of organic compounds including hydrocarbons and dioxins. Moreover, limited skills and lack of coherent regulation may also result in potential contamination because of inappropriate crop management (e.g. with reference to pesticide use). Nonetheless, strategies for counterbalancing or avoiding pollutions have been developed specifically for urban agriculture, e.g. through the adoption of soilless systems whenever soils are not suitable for crop production (Pennisi et al. 2016).

Another crucial innovative element associated with UA involves its economic dimension and the forms that it takes. Urban farmers benefit from the proximity to their con-sumers by exploring creative new business forms and relationships, and often progress beyond the potential cost-reduction offered by the possible short supply chains (e.g. solidarity buying groups and farmers markets). In the so-called Community Supported Agriculture (CSA) schemes, the boundary between consumers and producers fades out, merging these categories within the so-called prosumers. Diversification schemes emerge (as for social cooperatives engaging in farming and catering), while UA projects that build their success on the differentiation of production towards niche food typologies also appear. Moreover, the strongly innovative connotations of UA projects (e.g. mushrooms grown on exhausted coffee grounds or potted basil plants prepared by using the aquaponics technique), contribute to a growth of experiences that feature research and development as a main core. Finally, some UA projects concentrate their business on providing cooking, slaughtering or farming workshops, rather than selling food per se.

Furthermore, there is a generational shift happening among urban food producers, as compared with traditional rural agriculture. Globally, the age of farmers has increased following a constant trend during the last few decades, with younger generations generally leaving their family farms to look for alternative jobs in cities. Urban farms, on the other hand, are generally managed by young entrepreneurs raised in the city, having a limited rural background, and are often highly open to technological innovations and smart agricultural techniques. This primarily enables the exploration of creativity in project design, as, for example, the international student challenge Urban Farm, ${ }^{1}$ in which international and interdisciplinary teams compete in re-designing vacant urban spaces into multifunctional farming systems. Moreover, urban farming promotes innovation and con-tributes to the needed modernisation of the whole agricultural sector, in order to target the global objective of a sustainable agriculture.

\section{References}

Gasperi D, Pennisi G, Rizzati N, Magrefi F, Bazzocchi G, Mezzacapo U, Centrone Stefani M, Sanyé-Mengual E, Orsini F, Gianquinto G (2016) Towards regenerated and productive vacant areas through urban horticulture: lessons from Bologna, Italy. Sustainability 8:1347. https://doi.org/10.3390/su8121347

Pennisi G, Orsini F, Gasperi D, Mancarella S, Sanoubar R, Vittori Antisari L, Vianello G, Gianquinto G (2016) Soilless system on peat reduce trace metals in urban grown food: unexpected evidence for a soil origin of plant contamination. Agron Sustain Dev 36:1-11. https://doi.org/10.1007/s13593-016-0391-9

Pennisi G, Sanyé-Mengual E, Orsini F, Crepaldi A, Nicola S, Ochoa J, Fernandez JA, Gianquinto G (2019) Modelling environmental burdens of indoor-grown vegetables and herbs as affected by red and blue LED lighting. Sustainability 11:4063. https://doi. org/10.3390/su11154063

Sanyé-Mengual E, Orsini F, Oliver-Solà J, Rieradevall J, Montero JI, Gianquinto G (2015) Techniques and crops for efficient rooftop gardens in Bologna, Italy. Agron Sustain Dev 35:1477-1488. https ://doi.org/10.1007/s13593-015-0331-0

Sanyé-Mengual E, Gasperi D, Michelon N, Orsini F, Ponchia G, Gianquinto $\mathrm{G}$ (2018) Eco-efficiency assessment and food security potential of home gardening: a case study in Padua, Italy. Sustainability 10:2124. https://doi.org/10.3390/su10072124

Sanyé-Mengual E, Specht K, Grapsa E, Orsini F, Gianquinto G (2019) How can innovation in urban agriculture contribute to sustainability? A characterization and evaluation study from five Western European cities. Sustainability 11:4221. https://doi.org/10.3390/ su11154221

Publisher's Note Springer Nature remains neutral with regard to jurisdictional claims in published maps and institutional affiliations.

\footnotetext{
${ }^{1}$ https://site.unibo.it/urban-farm/en, accessed on June 10, 2020.
} 